\title{
An Atypical Case of Progressive Supranuclear Palsy
}

\author{
Andrew J. Gomori and Anders A.F. Sima
}

\begin{abstract}
SUMMARY: We report a 59 year old woman who presented with double vision, nuchal pain and mild dementia. On neurological examination she demonstrated third, sixth and seventh nerve palsies and ataxia. Following intravenous ACTH and oral prednisone therapy she showed a remarkable recovery which left her with only a left facial weakness. She remained well for two years. She then developed bulbar palsy and profound dementia. Pathological examination revealed progressive supranuclear palsy (PSP). This patient demonstrated a greater variability in the course of PSP than has previously been recognized.
\end{abstract}

RÉSUMÉ: Nous rapportons le cas d'une femme de 59 ans se présentant avec diplopie, douleur à la nuque et une démence légère. L'examen neurologique montrait des parésies du 3e, 6e et VII nerfs crâniens. Après l'administration intraveineuse d'ACTH et une thérapie orale avec Prednisone elle montra une rémission remarquable qui ne laissa qu'une faiblesse faciale. Elle fut bien pour 2 ans et développa ensuite une parésie bulbaire et une démence profonde. L'examen pathologique révéla une paralysie supranucléaire progressive (PSP). Son évolution fut plus oscillatoire que ce qu'on avait décidé auparavant.

Can. J. Neurol. Sci. 1984; 11:48-52

The clinical and pathologic features of progressive supranuclear palsy (PSP) were first described by Richardson, Steele, and Olszewski (Richardson et al., 1963; Steele et al., 1964). Several subsequent reports have provided additional details concerning this disorder (David et al., 1968; Behrman et al., 1969; Pfaffenbach et al., 1972; Steele, 1972; Perkin et al., 1978). The disease is characterized by supranuclear ophthalmoplegia, pseudobulbar palsy, nuchal dystonia, cerebellar and pyramidal signs and progressive dementia. It follows a progressive and relentless course ranging from two to ten years in duration. The characteristic pathological changes are cell loss, neurofibrillary degeneration and gliosis in brainstem, diencephalic and cerebellar nuclei.

The pathognomonic ultrastructural finding is neurofibrillary tangles consisting of $15 \mathrm{~nm}$ straight tubules. (Tellez-Nagel and Wisniewski, 1973; Roy et al., 1974; Powell et al., 1974). We report a patient with an unusual presentation of the disease and an atypical course. She had a two year remission followed by a rapid terminal course. Pathological examination revealed the classical abnormalities.

\section{CASE REPORT}

A 59 year old woman was admitted to the Health Sciences Centre, Winnipeg, in May of 1980 . She had been well until two weeks prior to admission when she complained of double vision and rapid onset of pain in the right shoulder and intrascapular region radiating to the occiput. There was no history of abdominal pain, toxic exposure, or recent viral infection. Although well educated, she was noted to be a vague and unreliable historian with poor recent memory. She answered slowly and she was unable to remember dates and recent political events.

Neurological examination revealed a partial left third nerve palsy with sparing of the pupil and the levator palpebrae muscle. There was partial paralysis of abduction of the left eye as well as a left lower motor neuron facial weakness. The limbs showed mild proximal weakness. Tendon reflexes were normal in the arms, exaggerated at the left knee and absent at the ankles. She had a wide based ataxic gait with truncal titubation. Apart from diminished appreciation of vibration in both feet, sensory testing was normal. While in hospital she developed a right lower motor neuron facial paralysis.

Bilateral vertebral and carotid angiograms were normal. A computed tomographic (CT) examination of the brain revealed mild ventricular dilatation. Motor nerve conduction velocities were normal in upper and lower limbs. Roentgenograms of the chest, skull, cervical, thoracic and lumbar spines were normal.

Complete blood count and erythrocyte sedimentation rate were normal. The cerebrospinal fluid (CSF) was under normal pressure and contained ten lymphocytes per cubic millimeter. CSF sugar and protein were normal and VDRL was non-reactive. The CSF gamma globulin was $1.14 \mathrm{mg} \%$ with an IgG/albumin ratio being normal at 0.12 . Microbiological examination of CSF revealed no bacteria, fungi or acid fast bacilli. A second lumbar puncture showed six lymphocytes, while a third CSF examination during the same hospitalization showed no cells, normal sugar and protein and negative cultures for bacteria, tubercle bacilli and fungi.

At this point she was thought to have multiple sclerosis. She was treated with 80 units of intravenous ACTH daily for two weeks. She was then switched to oral prednisone $50 \mathrm{mg}$ daily, which was tapered over the next several weeks and then discontinued. By the time of discharge after 4 weeks hospitalization she showed considerable recovery of extraocular eye movements and her gait and balance had returned to normal. In February 1981 she complained of intrascapular and neck pain and of burning sensations in the legs which cleared after a few days. Tendon reflexes and sensory examination were unchanged. There was minimal left facial weakness as well as intermittent left hemifacial spasm. In April of 1982 she had a single generalized seizure and was placed on prednisone and phenytoin by her family physician. When examined by one of us (A.J.G.) she had difficulty finding words as well as a comprehension deficit and a fluent aphasia. Apart from diminished arm swinging during walking and a residual left facial weakness, there were no new neurologic abnormalities.

From the Sections of Neurology, Department of Medicine (Dr. Gomori) and Neuropathology. Department of Pathology (Dr. Sima), University of Manitoba and Health Sciences Centre, Winnipeg, Manitoba

Presented at the 18th Canadian Congress of Neurological Sciences Meeting in St. John's. Newfoundland. June 1983

Received July 12,1983. Accepted in revised form November 3, 1983

Reprint requests to: Dr. A.J. Gomori, 1516 Medical Arts Building, 233 Kennedy Street, Winnipeg. Manitoba R3C 3J5 Canada 
An electroencephalogram showed intermittent bilateral polymorphic and arrhythmic delta activity most pronounced in the left temporal region. Brainstem auditory evoked potentials and pattern reversal visual evoked potentials showed normal latencies and amplitudes. CT-scan of the brain was unchanged.

The patient was not examined by us again, but we were informed that she developed a gradually progressive course with dementia and inability to move her eyes in any direction. In June 1982, she was admitted to a local hospital because of difficulty swallowing and aspiration. Terminally she was in a helpless bedridden state and died of bronchopneumonia a month later. Her brain was sent to us for examination.

\section{Pathology}

Gross Examination of the Brain. The brain weighed 1250 grams in the formalin fixed state. The meninges were thin and translucent. Coronal sections revealed mild dilatation of the ventricles. The cerebral cortex, white matter, thalamic and lenticular nuclei appeared normal. Sections of the brainstem showed pallor of the substantia nigra. The cerebellum was unremarkable on sectioning. The spinal cord revealed no gross abnormalities.

Light Microscopic Examination. No demyelinated plaques suggestive of multiple sclerosis were found in the cerebrum, cerebellum, brainstem or spinal cord, and no changes indicative of encephalitis or vasculitis could be demonstrated. Widespread neurofibrillary tangles were found in nuclei of the diencephalon, brainstem and cerebellum. They consisted of argyrophilic cytoplasmic inclusions of either flame-shaped or globoid types. They were most numerous in the inferior olivary, the dentate (Figure 1), the accessory cuneate, the subthalamic nuclei, and in the substantia nigra (Figure 2). They were also found in the zona incerta, the red nucleus, the periaqueductal grey matter and in the dorsal raphe nucleus and locus ceruleus of the pons, and in the vestibular and ambigui nuclei of the medulla.

In addition, a few tangles were identified in the medial globus pallidus, and in the anterior and reticular nuclear complexes of

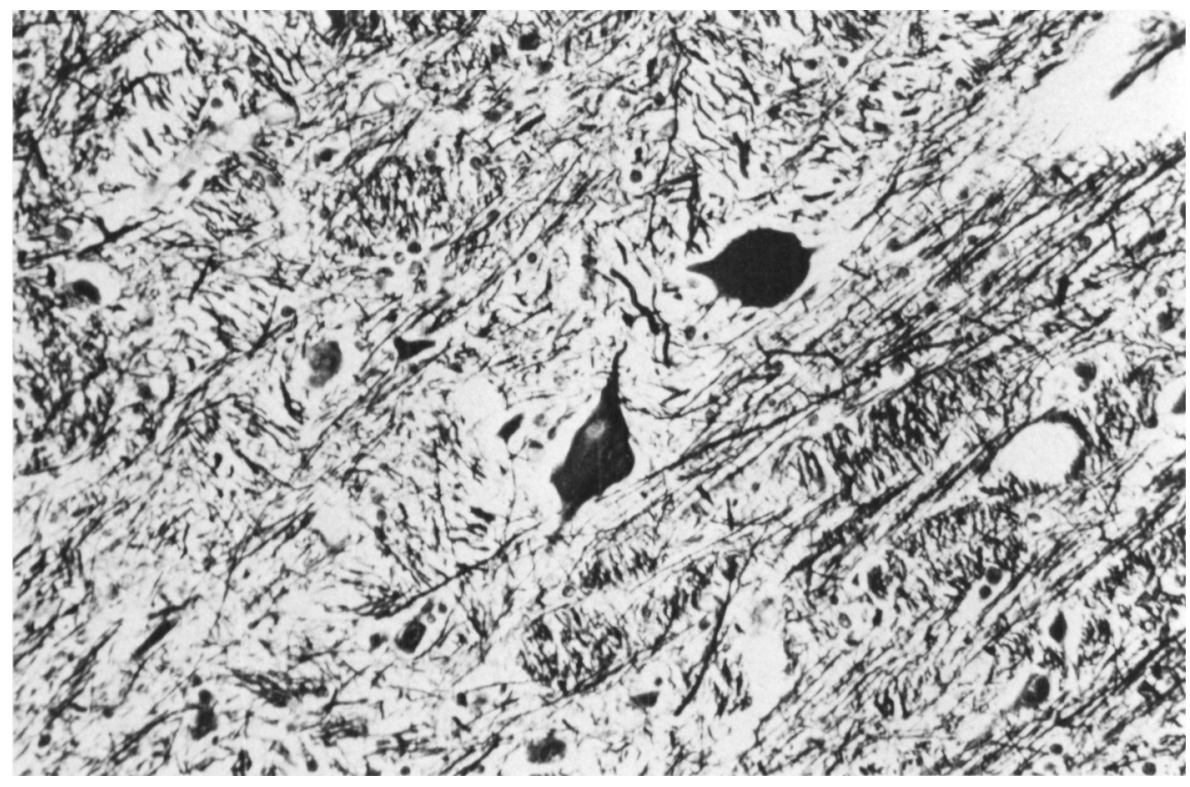

Figure I-Dentate mucleus showing two neurons containing neurofibrillary tangles and a moderate neuronal loss. (Bielschow'sky's silver stain). Mag. $730 \times$

Figure 2 - Detail of a substantia nigra neuron showing most of the cytoplasm occupied by globoid neurofibrillary tangle. (Bielschowsky's silver stain). Mag $1340 \times$

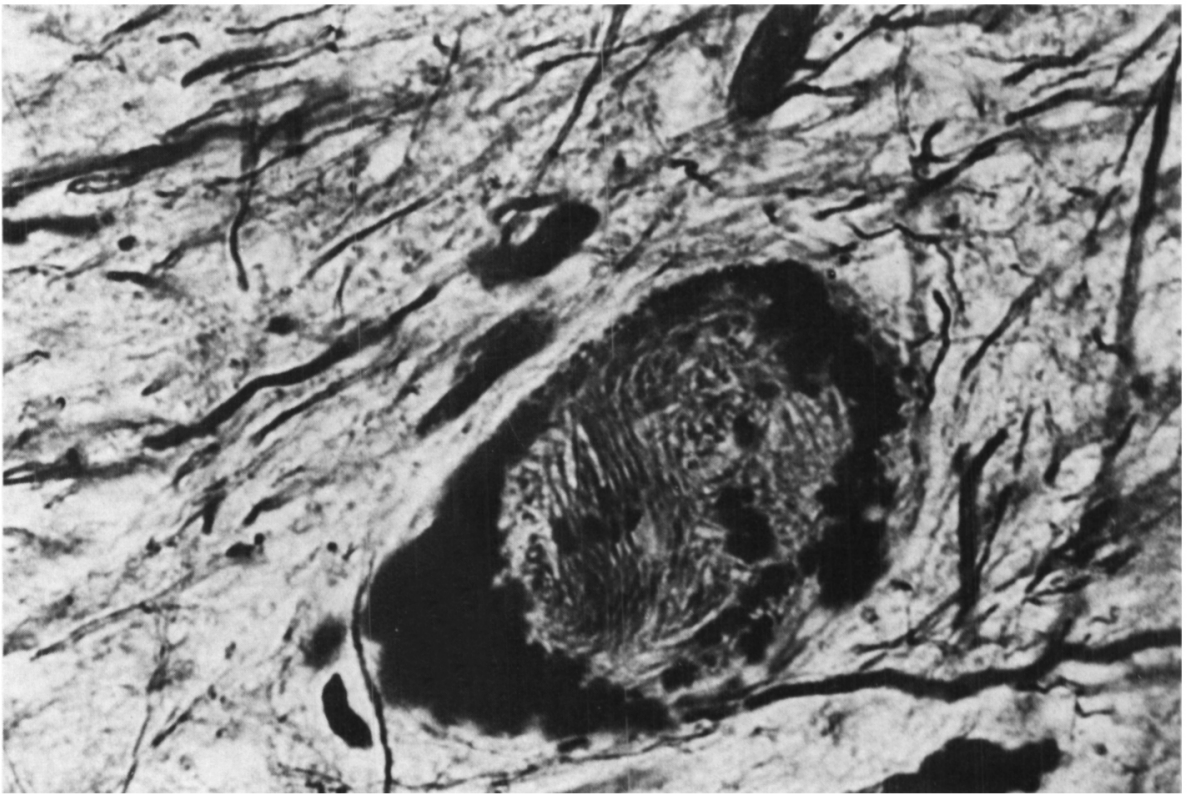


the thalamus. Furthermore, tangles were demonstrated in the fourth and sixth cranial nerve nuclei. The third cranial nerve nuclei appeared unremarkable, apart from the occasional tangle. The seventh cranial nerve nuclei showed no tangles but marked neuronal loss, and preserved neurons revealed central chromatolysis (Figure 3 ). The exit tracts of the third and the seventh nerves showed moderate myelin pallor. The substantia nigra and the subthalamic nuclei showed moderate to marked neuronal loss and astrogliosis. The substantia nigra also revealed neurons containing Lewy bodies (Figure 4).

The hippocampi and cerebral cortex appeared unremarkable and failed to show any neurofibrillary tangles. The intensity of neurofibrillary tangle involvement and severity of neuronal loss and gliosis in various nuclei are listed in Table 1. Peripheral nerves were not available for examination.

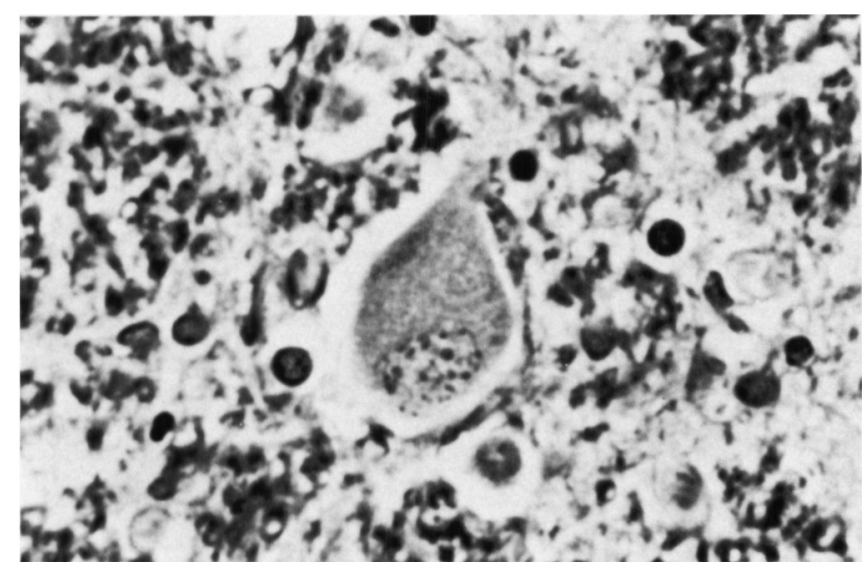

Figure 3 - Central chromatolysis in a preserved neuron of the seventh nucleus. (Hematoxylin-Eosin (H-E) and Luxol-fast-blue (LFB). Mag. $920 \times$

\section{Electronmicroscopy}

Tissue from the subthalamic nucleus, locus ceruleus and substantia nigra were processed for electronmicroscopy. Examination of these revealed the presence of focal cytoplasmic accumulation of straight tubules which were beaded with granules (Figure 5). No parahelical filaments were demonstrated. The straight tubules revealed a mean diameter of $16.2 \pm 1.4 \mathrm{~nm}$.

\section{Discussion}

The pathological findings in this patient were typical of PSP (Steele et al., 1964; Jellinger, 1971; Steele, 1972). This diagnosis was confirmed ultrastructurally by the presence of straight intracytoplasmic tubules measuring approximately $15 \mathrm{~nm}$ (TellezNagel and Wisniewski, 1973; Roy et al., 1974; Tomonaga, 1977).

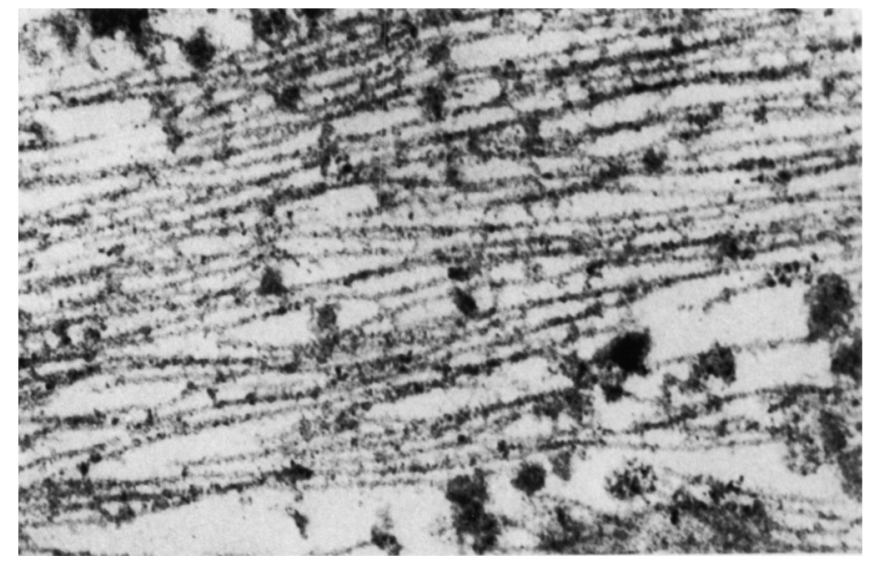

Figure 5 - Electronmicrograph of a neurofibrillary tangle in the substantia nigra. The tangle consists of straight tubules which measured a mean diameter of $16.2 \mathrm{~nm}$. Note granular beading of the individual tubules. Mag. $83.700 \times$

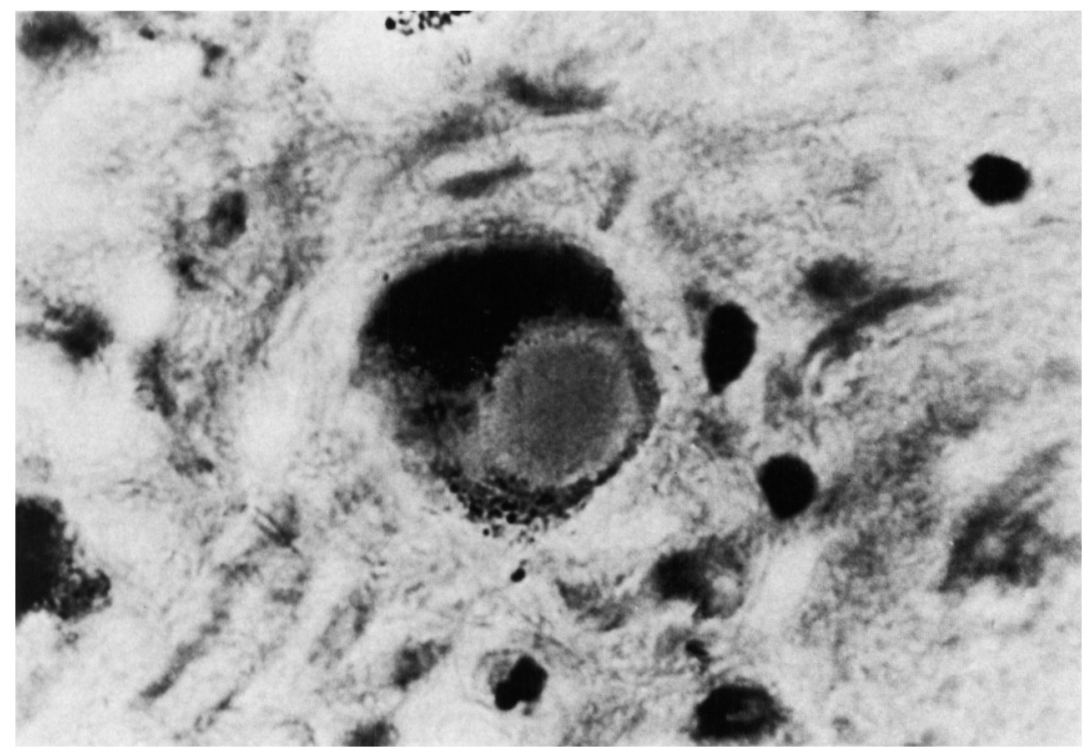

Figure 4 - Mature Lewy body in the substantia nigra. (H-E and LFB). Mag. I840X 
PSP is of unknown etiology and progresses in two to ten years to severe physical disability, dementia, and death. Temporary improvement has been noted, often coinciding with various treatments and lasting from weeks to months (Derenzi and Vignolo, 1969; Haldeman et al., 1981; Rafal and Grimm, 1981; Jackson et al., 1983). The clinical picture has been well documented (Steele et al., 1964; Albert et al., 1974; Perkin et al., 1978). The main features are impairment of voluntary vertical eye movements, difficulties with locomotion, balance, speech, swallowing and the development of dementia. Occasionally, absence of the typical eye signs may cause delay in the diagnosis (Perkin et al., 1978; Nuwer, 1981). Other features are slow, labored, slurred speech and cerebellar dysfunction. Several authors have documented involvement of cranial motor nuclei with neuronal loss of the third, fourth and sixth nuclei as well as demyelinization of their emerging nerves (Blumenthal and Miller, 1969; Ishino et al., 1974). These findings are similar to those found in our patient who showed lower motor neuron involvement of the third, sixth and seventh cranial nerves, all verified on pathological examination. The initial clinical features of double vision and unilateral cranial nerve symptoms in our patient were atypical. At this stage she showed mild dementia and complained of nuchal pain. Only at the terminal state did she show gaze palsy as well as profound dementia.

Since peripheral nerves were not examined pathologically, the coexistence of a peripheral nerve disorder, such as acute intermittent porphyria or the Fisher variant of Guillain-Barré syndrome, cannot be excluded. However, the normal nerve conduction velocity and normal CSF protein as well as the lack of further clinical evidence do not support these possibilities.

In PSP defective voluntary conjugate gaze with preservation of reflex eye movements is due to supranuclear lesions involving

Table 1: Intensity of neurofibrillary tangles and severity of neuronal loss and gllosis in various nuclel.

\begin{tabular}{|c|c|c|c|c|}
\hline SITE* & $\begin{array}{l}\text { Intensity } \\
\text { of neuro- } \\
\text { fibrillary } \\
\text { tangles }\end{array}$ & $\begin{array}{l}\text { Neuronal } \\
\text { loss }\end{array}$ & Gliosis & \\
\hline Anterior thalamic nucleus & + & - & - & \\
\hline $\begin{array}{l}\text { Reticular nucleus of } \\
\text { thalamus }\end{array}$ & + & - & - & \\
\hline Medial globus pallidus & $+t$ & ++ & + & \\
\hline Substantia innominata & + & + & - & \\
\hline Subthalamic nucleus & +++ & +++ & ++ & \\
\hline Zona incerta & ++ & + & - & \\
\hline Periaqueductal grey matter & $+t$ & + & + & \\
\hline Third nucleus & + & - & - & \\
\hline Fourth nucleus & ++ & + & - & \\
\hline Red nucleus & ++ & + & - & \\
\hline Substantia nigra: & & & & \\
\hline pars reticularis & +++ & $+t$ & $+t$ & $(+$ Lewy \\
\hline pars compacta & - & ++ & ++ & bodies) \\
\hline Sixth nucleus & ++ & + & - & \\
\hline Seventh nucleus & - & +++ & ++ & \\
\hline Dorsal raphae nucleus & ++ & - & - & \\
\hline Locus ceruleus & +++ & ++ & ++ & \\
\hline Inferior olivary nucleus & $+t+$ & + & + & \\
\hline Lateral vestibular nucleus & ++ & - & - & \\
\hline Ambiguus nucleus & $+t$ & + & + & \\
\hline Accessory cuneate nucleus & $++t$ & ++ & ++ & \\
\hline Dentate nucleus & +++ & ++ & + & \\
\hline
\end{tabular}

diencephalic and midbrain structures as in our patient. The lesions are usually bilateral, thus vertical eye movements can similarly be affected (Bender, 1980).

The dementia in our patient may have been due in part to lesions of the thalamomesencephalic junction, resulting in a disconnection of the ascending impulses from the mesencephalic reticular formation (Albert, 1978; Albert et al., 1974; Segarra, 1970). In addition, there may have been biochemical disorders involving cortical neurons not evident on pathologic examination (Drachman, 1981).

While receiving intravenous ACTH therapy and tapering doses of prednisone the patient showed a remarkable recovery. When she was discharged from hospital she had only a mild residual facial weakness. This remission lasted for two years before she developed a rapidly fatal progressive course.

Whether her improvement and long remission were an effect of the therapy is not known. The atypical presentation and prolonged remission in this patient indicate a greater variability in the natural course of the Steele-Richardson-Olszewski syndrome than has been previously recognized.

\section{ACKNOWLEDGEMENTS}

We are indebted to Dr. R.T. Ross, who provided helpful comments, and to Mrs. J. McKane for preparing this manuscript.

\section{REFERENCES}

Albert, M.L. (1978). Subcortical dementia. In: Alzheimer's disease: senile dementia and related disorders (Aging, Vol 7). Edited by Katzman, R., Terry, R.D. and Bick, K.L.. New York: Raven Press, pp. 173-180.

Albert, M.L., Feldman, R.G. and Willis, A.L. (1974). The subcortical dementia of progressive supranuclear palsy. J. Neurol. Neurosurg. Psychiatry, 37:121-130.

Behrman, S., Carrol, J.D.. Janofa, I., Matthews, W.B. (1969). Progressive supranuclear palsy. Clinico-pathological study of four cases. Brain, 92:663-678.

Bender, M.B. (1980). Brain control of conjugate horizontal and vertical eye movements. Brain, 103:23-69.

Blumenthal, H. and Miller, C. (1969). Motor nuclear involvement in progressive supranuclear palsy. Arch. Neurol., 20:362-367.

David, N.J., Mackey, E.A., Smith, J.L. (1968). Further observations in progressive supranuclear palsy. Neurology 18:349-356.

Derenzi, E. and Vignolo, L.A. (1969). L-Dopa for progressive supranuclear palsy. Lancet, 2:1359.

Drachman, D.A. (1981). The cholinergic system, memory and aging. In: Brain neurotransmitters and receptors in aging and age related disorders (Aging, vol. 17), Edited by Enna, S.J., Samorajski, T. and Beer, B. New York, Raven Press, pp. 255-268.

Haldeman, S., Goldman, J.W., Hyde, J. and Pribam, H.F.W. (1981). Progressive supranuclear palsy, computed tomography, and response to anti-parkinsonian drugs. Neurology (NY), 31:442-445.

Ishino, H., Higashy, H., Kuroda, S., Yabuki, S., Hayahara, T., Otsuki, S., (1974). Motor nuclear involvement in progressive supranuclear palsy. J. Neurol Sci 22:233-244.

Jackson, J.A., Jankovic, J. and Ford, J. (1983). Progressive supranuclear palsy: Clinical features and response to treatment in 16 patients. Ann. Neurol., 13:273-278.

Jellinger, K. (1971). Progressive supranuclear palsy (subcortical argyrophilic dystrophy). Acta. Neuropathol., (Berl) 19:347-352.

Nuwer, M.R. (1981). Progressive supranuclear palsy despite normal eye movements. Arch. Neurol., 38:784. 
Perkin, G.D., Lees, A.J., Stern, G.M. and Kocen, R.S. (1978). Problems in the diagnosis of progressive supranuclear palsy (SteeleRichardson-Olszewski syndrome). Can. J. Neurol. Sci., 5:167-173.

Pfaffenbach, D.D., Layton, D.D. and Kearns, T.P. (1972). Ocular manifestations in progressive supranuclear palsy. Am. J. Ophthalmol., 74:1179-1184

Powell, H.C., London, G.W. and Lampert, P.W. (1974). Neurofibrillary tangles in progressive supranuclear palsy: electron microscopic observations. J. Neuropathol. Exp. Neurol., 33:98-106

Rafal, R.C. and Grimm, R.J. (1981). Progressive supranuclear palsy: functional analysis of the response to methysergide and antiparkinsonian agents. Neurology (NY), 31:1507-1518.

Richardson, J.D., Steele, J. and Olszewski, J. (1963). Supranuclear ophthalmoplegia, pseudobulbar palsy, nuchal dystonia and dementia. Trans. Am. Neurol. Assoc. 88:25-27.

Roy, S., Datta, C.K., Hirano, A., Ghatak, N.R. and Zimmerman, H. (1974). Electron microscopic study of neurofibrillary tangles in
Steele-Richardson-OlszewskiSyndrome. Acta. Neuropathol. (Berl) 29:175-179.

Segarra, J.M. (1970). Cerebral vascular disease and behaviour. Arch. Neurol. 22:408-418.

Steele, J.C., Richardson, J.C. and Olszewski, J. (1964). Progressive supranuclear palsy: a heterogenous degeneration involving the brainstem, basal ganglia and cerebellum with vertical gaze and pseudo-bulbar palsy, nuchal dystonia and dementia. Arch. Neurol. 10:333-359.

Steele, J.C. (1972). Progressive supranuclear palsy. Brain, 95:693-704.

Tellez-Nagel, I. and Wisniewski, H.M. (1973). Ultrastructure of neurofibrillary tangles in Steele-Richardson-Olszewski syndrome. Arch. Neurol., 27:324-327.

Tomonaga, M. (1977). Ultrastructure of neurofibrillary tangles in progressive supranuclear palsy. Acta. Neuropathol. (Berl) 37:177-181. 